\title{
International Reliability Analysis in Distribution Networks
}

\author{
A. Sumper ${ }^{1}$, A. Sudrià ${ }^{1}$ and F. Ferrer ${ }^{1}$ \\ ${ }^{1}$ Centre d'Innovació Tecnològica en Convertidors Estàtics i Accionaments \\ CITCEA, Universitat Politècnica de Catalunya \\ Av. Diagonal, 647. Pavelló A; 08028 Barcelona (Spain) \\ phone:+34 9340167 27, fax:+34 9340174 33, \\ e-mail: sumper@citcea.upc.es; sudria@citcea.upc.es; ferrer@citcea.upc.es
}

\begin{abstract}
.
This work intents to introduce a new concept for perceived power quality and the relationship between availability of supply and perceived power quality. After that it attempts to give an overview of the interruption indices used nowadays and to compare system reliability in Europe by using interruption indices. Then we will determine the factors of influence in these indices and finally give an overview of the measures necessary in order to decrease interruption indices.
\end{abstract}

\section{Key words}

Quality of Supply, Perceived Power Quality, Distribution Networks Reliability, Power Quality

\section{Introduction}

This paper describes the relationship between the perceived power quality, distribution reliability and interruption indices. It starts with a new conceptual view of the perceived power quality, tackles the used indices for availability of supply, gives an overview on the availability in Europe and ends with the measures necessary in order to improve network reliability.

\section{New conceptual View of Perceived Power Quality}

Nowadays the quality of electric power is indispensable in any modern economy. But there is a lot of confusion about what kind of aspects should be included in Power Quality. First of all, we can state that power quality should be seen from the customer point of view; therefore it should be named the perceived power quality. In other words, the customer experiences a lack of expected service from his apparatus and as a result, detects the lack of power quality. Therefore we detect two main agents in power quality: the utility and the costumer.

From the utility point-of-view, we can divide power quality into three major categories:
1) Commercial quality of power
2) Availability of power supply
3) Waveform quality

From the customer point-of-view, we have two major aspects to consider:
4) Reliability of the customer installation
5) Compatibility level of the customer apparatus

Figure 1 shows the relationship between the different factors in power quality. 


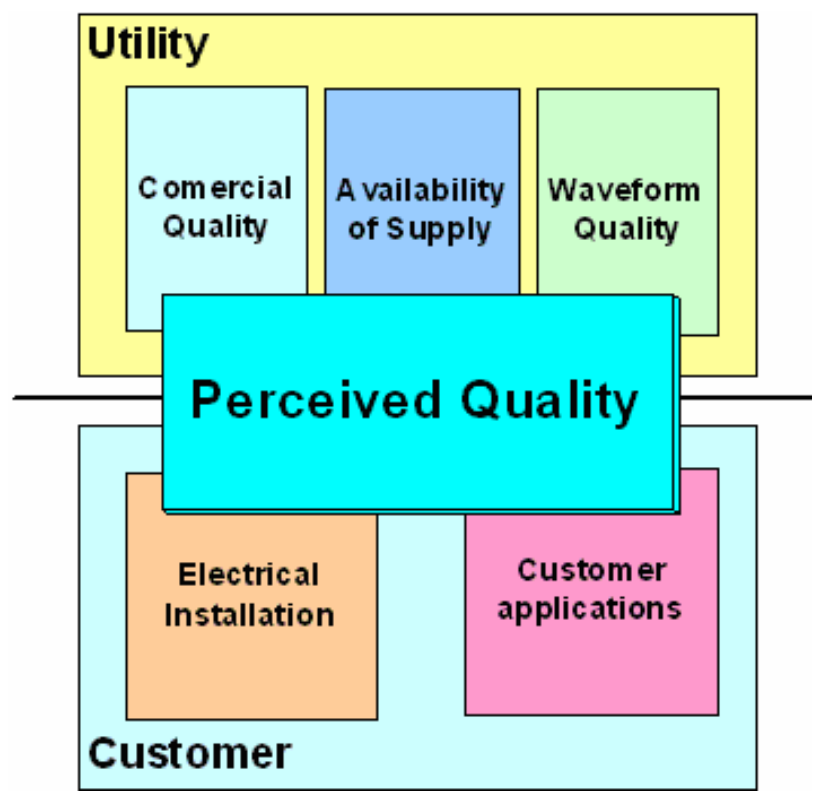

Fig. 1. Conceptual view of perceived power quality

\section{A. Commercial quality of power}

Commercial quality of power is the only non-technical part of the perceived power quality, and it defines the quality of the commercial relationship between the customer and the utility.

\section{B. Availability of power supply}

Availability or continuity of supply is characterized by the number and duration of supply interruptions. Supply interruptions are unavoidable in electric power distribution and are defined in the standard EN 50160 as interruptions longer than 3 minutes. Availability refers to uninterrupted power supply.

\section{Waveform quality}

Waveform quality is the inherent quality of the power, and it is measured in terms of acceptable values of voltage and frequency. Waveform quality is often mistaken for the term power quality, but it should be emphasized that waveform distortion (e.g. square waveform output from a UPS) does not lead to a malfunction of the customer apparatus.

\section{Reliability of the customer installation}

The responsibility of the utility ends at the point of common coupling (PCC). The customer installation between the PCC and the customer apparatus is influential on for the perceived power quality. Installing UPS, redundancy, an adequate grounding system, standby systems, harmonic filters is decisive for the overall power quality of the installation.

\section{E. Compatibility level of the customer apparatus}

The customer apparatus is characterized by the emission level and the immunity level. The Emission Level is the level of disturbance produced by the load. The immunity level is the maximum value of disturbance present in the network without degrading the behavior of the apparatus.

\section{Availability of supply indices}

In respect to the effects of interruption of supply on a customer, the interruptions are classified in planned and unplanned interruptions, as well as, in short and long interruptions. Long interruptions are considered as those longer than 3 minutes. In order to quantify the effects of long interruption, interruption indices are defined as Interruption Frequency, Supply Unavailability and Interruption Duration.

Interruption frequency represents the number of interruptions on average per year per customer. Supply unavailability describes the number of minutes without supply on average per year per customer, and interruption duration is the average duration of customer interruptions.

The three methodologies for calculation interruption indices are based on the number of customers, the connected power and the number of substations (transformers). UNIPEDE [1] and IEEE [2] have defined acronyms for indices calculated by one of the specific methodologies. Several national regulators in Europe have defined their own acronyms for the interruption indices. All of these methodologies are well-known and are exposed in the following references: [1], [2], [3], [4]. The following table shows the acronyms used for the interruption indices.

TABLE I. - Interruption indices used

\begin{tabular}{|c|c|c|c|c|}
\hline Based & County & $\begin{array}{c}\text { Interruption } \\
\text { frequency }\end{array}$ & Unavailability & $\begin{array}{c}\text { Interruption } \\
\text { duration }\end{array}$ \\
\hline \multirow{2}{*}{$\begin{array}{c}\text { Cust- } \\
\text { omers }\end{array}$} & IEEE & SAIFI & SAIDI & CAIDI \\
\cline { 2 - 5 } & $\begin{array}{c}\text { Great } \\
\text { Britain }\end{array}$ & $\begin{array}{c}\text { Customer } \\
\text { Interruptions }\end{array}$ & $\begin{array}{c}\text { Customer } \\
\text { Minutes Lost }\end{array}$ & - \\
\hline \multirow{2}{*}{$\begin{array}{c}\text { Con- } \\
\text { nected } \\
\text { power }\end{array}$} & \begin{tabular}{c} 
IEEE \\
\cline { 2 - 5 }
\end{tabular} & ASIFI & ASIDI & - \\
\hline
\end{tabular}

\section{Availability in Europe}

In Europe, every country applies their own criteria in order to calculate the supply indices; there are differences in the methodology, voltage level and proportion of network included. In many cases, the indices are calculated by distribution companies, and in other cases, company indices are confidential. In general, it can be said that the data in not homogeneous; few years are represented; and the quality of data is questionable. Therefore, the values available should be taken with caution and benchmarking these crude values could lead to inaccurate conclusions. But they are providing a point of reference from which to compare different practices etc. in different countries. Table II compares the national mean values of the interruption frequency and unavailability [5] in different European countries, while Figure 2 shows the results in a graphical manner. The city of Barcelona is also included in these statistics. 
TABLE II. - European Availability Benchmark

\begin{tabular}{|l|c|c|}
\hline County & $\begin{array}{c}\text { Interruption } \\
\text { frequency } \\
{[1 / \mathrm{a}]}\end{array}$ & $\begin{array}{c}\text { Unavailability } \\
{[\mathrm{min} / \mathrm{a}]}\end{array}$ \\
\hline Austria & 0,59 & 35,23 \\
\hline Barcelona city & 2,28 & 107,60 \\
\hline Belgium & 0,90 & 42,25 \\
\hline Finland & 4,06 & 182,67 \\
\hline France & 1,21 & 53,33 \\
\hline Germany & 0,27 & 37,00 \\
\hline Great Britain & 0,77 & 70,09 \\
\hline Ireland & 1,34 & 235,67 \\
\hline Italy & 3,83 & 202,85 \\
\hline Norway & 2,73 & 218,00 \\
\hline Spain & 2,98 & 153,00 \\
\hline Sweden & 2,07 & 99,00 \\
\hline The Netherlands & 0,38 & 27,50 \\
\hline
\end{tabular}

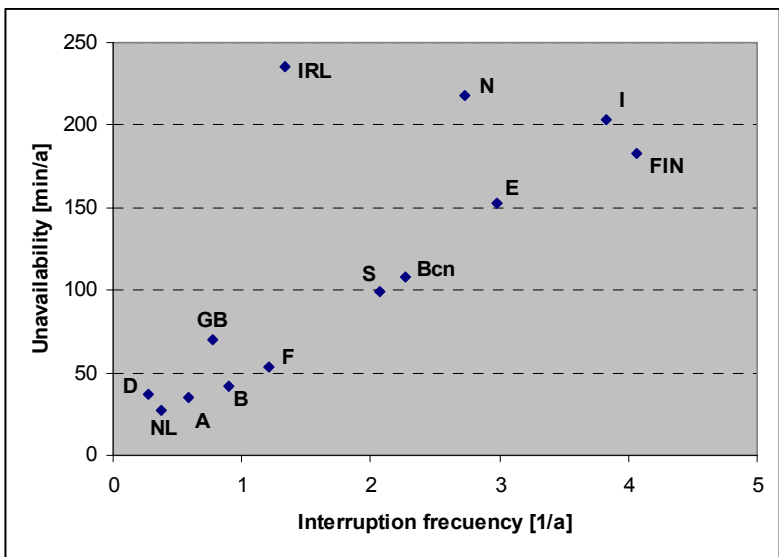

Fig. 2. Unavailability vs. Interruption frequency in several European countries

Generally, it could be said that the values of interruption indices have a great dispersion and there is a great variety between different countries. It has been shown [6] that even when distribution networks have very similar networks, there can be significant differences in interruption indices. Therefore a range of influential factors can be determined which may explain the variations of indices. In short, these factors can be separated into two classes: inherited and inherent factors [7].

\section{A. Inherited factors}

The inherited factors are derived from the differences that the distribution companies have inherited due to their long term network design. It includes differences in the design and configuration of the network, such as length and the degree of interconnection. For example, long overhead lines probably have a larger number of faults than shorter lines; in general, cable networks are more reliable than overhead lines.
The most important inherited factors are:

$\begin{array}{ll}\text { - } & \text { Feeder length } \\ \text { - } & \text { Voltage level in MV } \\ \text { - } & \text { Secentionalizing } \\ \quad & \text { Rate of automatization } \\ & \text { Rate of interconnection between feeders }\end{array}$

\section{B. Inherent factors}

The inherent factors are related to the supply area in which a distribution company is serving. It includes differences in topographic, climatic, and demographic factors, such as the level of customer density. For example, urban areas interruptions will affect more customers than in rural areas; on the other hand, in urban areas, the possibility of interconnection is better.

The most important inherent factors are:

$\begin{array}{ll}\text { - } & \text { Lightning } \\ \text { - } & \text { Air pollution and salt contamination } \\ & \text { Climatic factors, like storms, ice storms, extreme } \\ \text { - } & \text { Anperatures, strong precipitations and floods } \\ \text { - } & \text { Vegetation } \\ \text { - } & \text { Customer density }\end{array}$

Figure 3 shows an example of influence of inherent factors which are affecting interruption indices. The red line marks the accumulated unavailability of a Spanish region by days, ranked from the most contribution to the least contribution. The blue line represents the lightning activity on the same days. It can be seen that there is a strong correlation between lightning activity and unavailability.

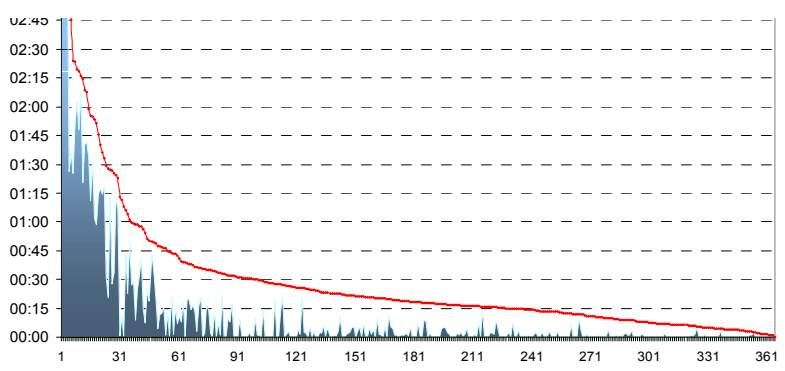

Fig. 3. Correlation between the unavailability and thunderstorm days in a Spanish region

Finally, it should be said that interruption indices are not homogeneous and comparisons between countries and companies should be made with caution. There is a trend to reward good network performance and to penalize below average performance in order to stimulate distribution companies to increase network reliability. Regulators should consider inherited and inherent factors when determining the network performance. 


\section{Distribution Network Reliability}

Until now, the objectives of network design have been to minimize distribution losses. However, by introducing interruption indices, the design criteria will change to include optimal network configuration, which will guarantee lower interruption indices. There are three possible strategies for decreasing interruption indices:

- $\quad$ Reduction of the number of faults

- Reduction of time of interruption

- $\quad$ Reduction of number of affected customers

\section{A. Reduction of the number of faults}

The reduction of the interruption frequency is possible by decreasing failure rates of the network component. For example, the reduction of the number of faults in an overhead line can be reached by a tree trimming program, which ensures the clearance distance. This will reduce the failure rate, and increase the system reliability and reduce interruption. A reduction of the number of interruptions leads to lower interruption indices.

In summary, the reduction of the number of faults causes a decrease of the frequency of interruptions and unavailability. In the following list, we can find the most important measures for reducing failure rates.

- Preventive maintenance

- Monitoring critical components

- Preventive replacement of components which have reached the end of their useful life

- Isolated or tree wires in overhead lines to prevent tree contact with the conductor

- Tree trimming and periodical trimming of the adjacent vegetation to prevent contact with the conductors

- Protection against animals contact with conductors

\section{B. Reduction of time of interruption}

The time of interruption is the time required to restore the power supply. A fault affected zone in the distribution network can be isolated from the healthy part of the network by disconnecting the affected sector. It is important that the switching actions of the restoring process are optimized in order to isolate the smallest possible section of network affected by the fault. This process does not reduce the time interruption in the fault affected zone, but it will provide a substantial improvement in the sector of the network that is not affected by the fault. Furthermore automated sectioning points will provide a more timely restoration of the power supply. If the restoration of the supply takes place in less than three minutes, the interruption is not considered as long interruption.

Time reduction of the time processes lead to a reduction in the unavailability indices, but do not show effects on interruption frequency.
The following list shows some of the most important measures for reducing the time of interruption:

- Distribution network automatization

- System reconfiguration after the fault

- Fault current detection in order to localize the fault in the network

- $\quad$ Faster crew response due to the implentation of an outage management system, travel time coordination and an increased number of crews and dispatch centers

\section{Reduction of number of affected customers}

Finally, due to the reduction of the number of customers affected customers by a fault it is possible to reduce the interruption frequency and the unavailability of a supply region. Possible reduction measures include:

- Permanent reconfiguration of the distribution network

- $\quad$ More protective elements (recloser etc.)

- Resonant transformer grounding.

Permanent reconfiguration is the reduction of the number of customers per feeder by adding more and shorter feeders per substation. More protective elements, such as reclosers, separate the fault affected network section from the healthy one and reduce the number of customers interrupted. Finally, resonant grounding with arc suppression coils in transformer stations reduces the number of temporary phase to earth faults in overhead networks.

\section{Conclusion}

The perceived power quality can be divided into five parts: commercial quality of the utility, availability of supply, waveform quality, customer installation and compatibility levels of the customer's apparatus. It is very important to consider that the customer apparatus and installation are influential on the power quality.

System reliability is expressed by interruption indices, which are applied in different ways around Europe; therefore, an international comparison of availability of supply should be viewed with reservation. In the future, when the quality of data is increased, the comparison should have more substance.

The variation of the interruption indices between countries and companies led us to the conclusion that the factors of influence on these indices and inherited and inherent.

Finally, decreasing fault rates, restoration time and number of affected customers will result in lower interruption indices and increase distribution system reliability. 


\section{Acknowledgement}

We would like to acknowledge the financial and technical support from ENDESA RED which made possible the research project on distribution system reliability.

\section{References}

[1] UNIPEDE, Distribution Study Committee, 50.05.DISQUAL, July 1997, Ref. 05005REN9733, pp4-5

[2] IEEE Power Engineering Society, IEEE Trial-Use Guide for Electric Power Distribution Reliability Indices, April 1999, New York, pp 3-7

[3] Boletín Oficial del Estado, ORDEN ECO/797/2002, de 22 de marzo, por la que se aprueba el procedimiento de medida y control de la continuidad de suministro eléctrico, pp14170-14171

[4] Council of European Energy Regulators (CEER), Working Group on Quality of Electricity Supply, SECOND BENCHMARKING REPORT ON QUALITY OF ELECTRICITY SUPPLY, pp24-25

[5] A. Sumper, A. Sudrià; Estudio comparativo de la calidad de suministro eléctrico en diversas regiones de la Unión Europea, CITCEA-UPC, Research Study, February 2004, pp 41-42

[6] OFGEM, Information and incentive program, Comparing quality of supply performance, October 2002, pp12-13

[7] V. Roberts and D. Russell, "Benchmarking the Performance of Distribution Networks", CIRED Conference 2003, Session2, No 67 